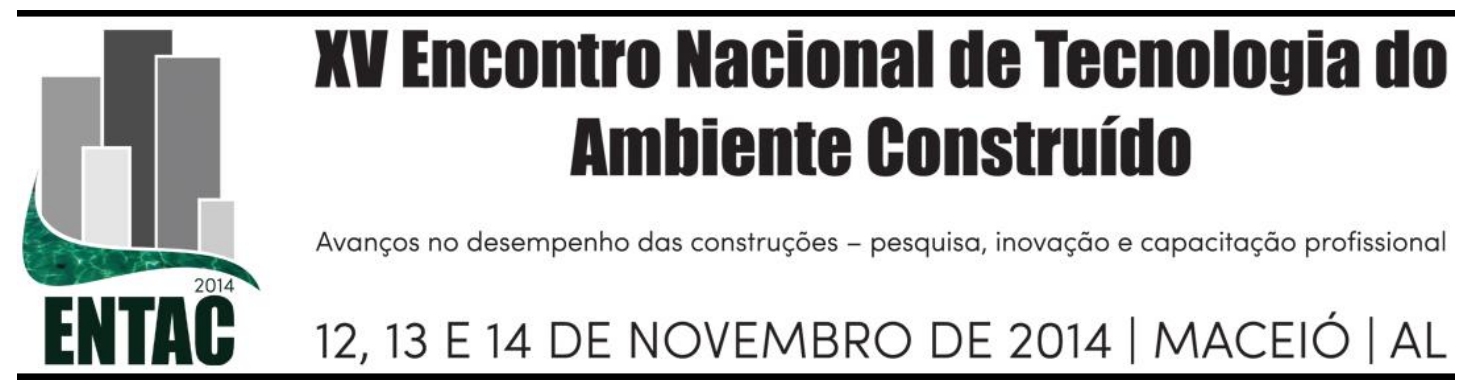

\title{
ESTUDO DE CASO: CUSTO DAS DECISÕES ARQUITETÔNICAS DAS OBRAS DA UNIVERSIDADE FEDERAL DE UBERLÂNDIA
}

\author{
SILVA, Melissa Mariana Ferreira (1); SANTOS, Antônio Carlos dos (2)
}

(1) Universidade Federal de Uberlândia (UFU), melissamarianas@gmail.com, (2) Universidade Federal de Uberlândia (UFU), acds@feciv.ufu.br

\begin{abstract}
RESUMO
Considerando a finalidade do edifício, observa-se que o projeto arquitetônico em sua concepção é marcado por muitos conceitos e posições diante do ambiente natural e construído. Para todo empreendimento, ao longo do processo de projeto, aspectos vinculados à interação com o lugar, à resolução do programa e ao papel da tecnologia são trabalhados e levados em consideração. Um dos fatores que mais exercem influência no custo das construções é a geometria do projeto. O objetivo desse estudo de caso é analisar as edificações que estão em execução ou foram executados nos campi da Universidade Federal de Uberlândia (UFU), aplicando-se alguns dos aspectos analisados por Mascaró (1995) quanto ao custo das decisões arquitetônicas para o projeto de hospitais que podem ser aplicados em edificações de uso público. Este estudo de caso foi desenvolvido na Diretoria de Infraestrutura (DIRIE) da UFU, em que foi feito um estudo dos custos das decisões arquitetônicas, por meio do projeto e orçamentos de três diferentes edificações denominadas 5SSM, 1AMC e 1BCG. Foram analisadas a estrutura básica a partir do ponto de vista econômico em que os custos de construção dos planos verticais, planos horizontais e instalações estavam dentro do esperado mas os elementos construtivos apresentavam uma diferença um pouco acentuada; o tamanho e a forma dos compartimentos nos custos das edificações em que pode-se diminuir dimensões ou alterar a forma do projeto e/ou utilizar materiais e elementos alternativos; a influência da variação de altura do edifício no custo de construção; e a variação do custo com o sistema de circulação em que deve-se repensar as formas alongadas dos blocos e compartimentos que causam incrementos de custos grandes (corredores). Para um projeto econômico o importante é pensar de forma a minimizar os custos prezando pela qualidade, estética e funcionalidade.
\end{abstract}

Palavras-chave: Projeto, custo, desempenho.

\begin{abstract}
Considering the purpose of the building, it is observed that the architectural design in its conception is marked by many concepts and positions on the natural and built environment. One of the factors that most influence the cost of the buildings is the design geometry. The objective of this case study is to analyze the edifications that are under construction or have been built on the campuses of the Federal University of Uberlândia (UFU), applying some of the aspects analyzed by Mascaro (1995) about the cost of the architectural decisions for the hospitals project that can be applied in edifications for public use. This case study was developed in the Department of Infrastructure (DIRIE) UFU : a study of the costs of architectural decisions was made, through the design and budget of three different buildings called 5SSM , IAMC and IBCG. There were analyzed the basic structure from the economic point of view that the costs of construction of vertical and horizontal planes and facilities were as expected but the building blocks presented a rather marked difference; the size and shape of compartments in the cost of the buildings in which it is possible to reduce the size or change the design shape and/or using alternative materials and components; the influence of the variation in height of the building on the construction cost ; and the variation of the cost with the circulation system that should rethink the stretched shapes of blocks and compartments that cause large increases costs (runners). For an economical design the important is to think to minimize the costs maintaining the quality, aesthetics and functionality.
\end{abstract}

Keywords: Design, cost, performance. 


\section{INTRODUÇÃ̃O}

Para a análise dos custos das decisões arquitetônicas, realizou-se um estudo da literatura, e os parâmetros utilizados foram os encontrados nas publicações de Juan Luiz Mascaró sobre o tema.

Sabe-se que a concepção do projeto arquitetônico leva em consideração a finalidade do edifício e é marcada por muitos conceitos e posições frente ao meio ambiente natural e construído. Segundo Mahfuz (2006 apud Cunha, 2008), até meados do século XVIII, a boa arquitetura seria aquela que apresentasse um equilíbrio entre os três componentes: solidez, adequação funcional (esfera racional) e beleza (componente estético); atualmente são três condições internas (programa, lugar e técnica de construção).

No projeto, o lugar é considerado base em múltiplas relações que o edifício estabelece com o local de intervenção; o programa estabelece relações entre espaços interiores e exteriores quanto à organização dos planos verticais e horizontais; a técnica de construção é vinculada à materialização e uso da edificação (Cunha, 2008). Assim, durante o processo de projeto, para o todo construído, são considerados e trabalhados aspectos ligados à interação com o lugar, a resolução do programa e ao papel da tecnologia na proposta.

Segundo Mascaró (2004) os edifícios completos são compostos por instalações e espaços agregados. Estes são criados por arquitetos e projetistas, e são formados pela interseção dos conjuntos de planos verticais e de planos horizontais, no ponto de vista geométrico.

A geometria do projeto é um dos fatores que mais influenciam no custo das edificações. Então, eventuais alterações na quantidade de planos e no seu distanciamento causam alterações nos custos (MASCARÓ, 2004). Ainda segundo Mascaró (1995), tradicionalmente, a visão de economia de custo de construção das edificações é devido à quantidade de área construída e qualidade da especificação dos materiais, mas há configurações de soluções arquitetônicas que influenciam nos custos.

Mascaró aplicou o custo das decisões arquitetônicas no projeto de hospitais (1995), e muitos dos aspectos analisados e estudados podem ser aplicados em edificações de uso público, como os blocos multiuso e de salas de aula de universidades.

Sendo assim, o objetivo desse estudo, foi analisar os blocos que estão em execução ou foram executados nos diversos campi da Universidade Federal de Uberlândia (UFU). A princípio foram estudados os edifícios denominados 1AMC, 1BCG e 5SSM.

\section{REVISÃO BIBLIOGRÁFICA}

As edificações foram analisadas segundo a estrutura básica a partir do ponto de vista econômico; o tamanho e a forma dos compartimentos do custo; a influência da variação da altura e do sistema de circulação do edifício no custo de construção.

Segundo Mascaró (1995), do ponto de vista de custo há uma divisão entre os espaços construídos e os equipamentos necessários para que o edifício cumpra sua função. E essas variam de forma diferente mesmo interligadas: o custo da circulação vertical varia se o projeto prevê, ou não, o uso de elevadores e o custo das instalações sanitárias varia com o número de banheiros. Assim, os custos dos espaços dependem das decisões dimensionais adotadas na edificação: comprimento, largura, altura do pé direito, número 
de pavimentos etc. Para minimizar o custo da construção, realiza-se a análise e altera-se a geometria do projeto, para que se minimize a quantidade de materiais utilizados.

Quando se preocupa com a redução de custos, diminui-se a qualidade através dos materiais e do tipo de execução do edifício ao invés de se repensar a forma e tamanho dos locais (MASCARÓ, 1995). A redução da superfície de um compartimento ou de um edifício nem sempre leva a uma redução nos custos, na mesma proporção que a superfície foi reduzida. Se há aumento na densidade de paredes, há aumento nos custos. Formas muito alongadas causam incrementos de custos grandes, o que acontece com corredores (áreas de circulação) e a solução não é diminuir as larguras destes e sim encurtá-los, ou até reformular o projeto.

O custo da construção de cada metro construído varia com a altura do edifício. A variação dos custos de construção em função da altura varia com a quantidade de pavimentos e a variação de altura do pé direito e com isso, o custo dos componentes dos planos verticais (alvenaria, acabamentos, isolamento, pilares, esquadrias). A economia dos custos de construção será muito pequena com a diminuição do pé-direito dos cômodos e de nenhuma forma deve ser colocado em risco o nível de habitabilidade dos locais na procura de economia causada por essa diminuição (MASCARÓ, 1995). Assim, diminuir o pé direito não há significativo ganho de economia, e só há diferença quanto a acústica dos compartimentos. O sistema de circulação é formado pela circulação vertical (escadas, rampas e elevadores) e horizontal (corredores de distribuição).

As edificações estudadas foram 1AMC (Figura 1), 1BCG (Figura 2) e 5SSM (Figura 3).

Figura 1 - Bloco 1AMC, em execução.

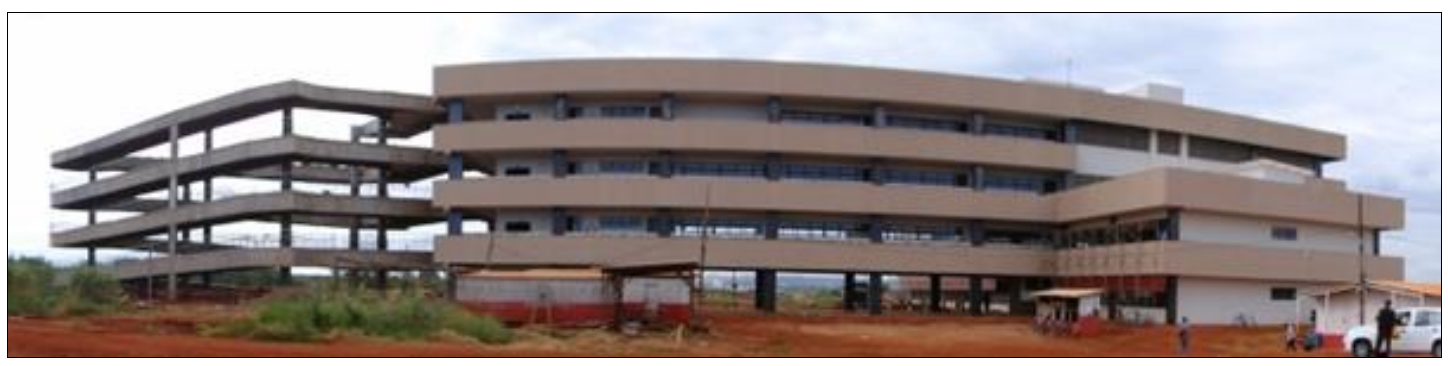

Fonte: UFU (2014).

Figura 2 - Bloco 1BCG, em execução.

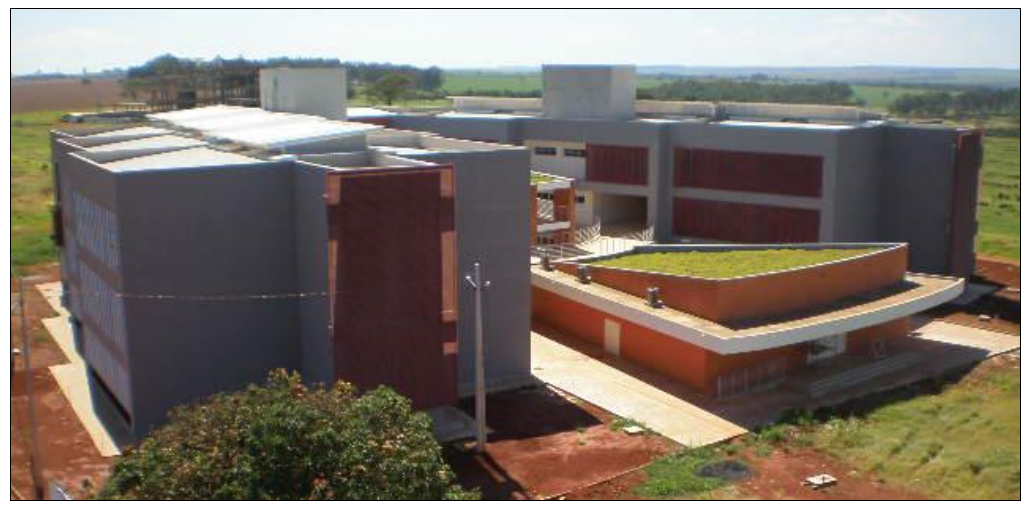

Fonte: UFU (2014). 
Figura 3 - Bloco 5SSM, entregue.

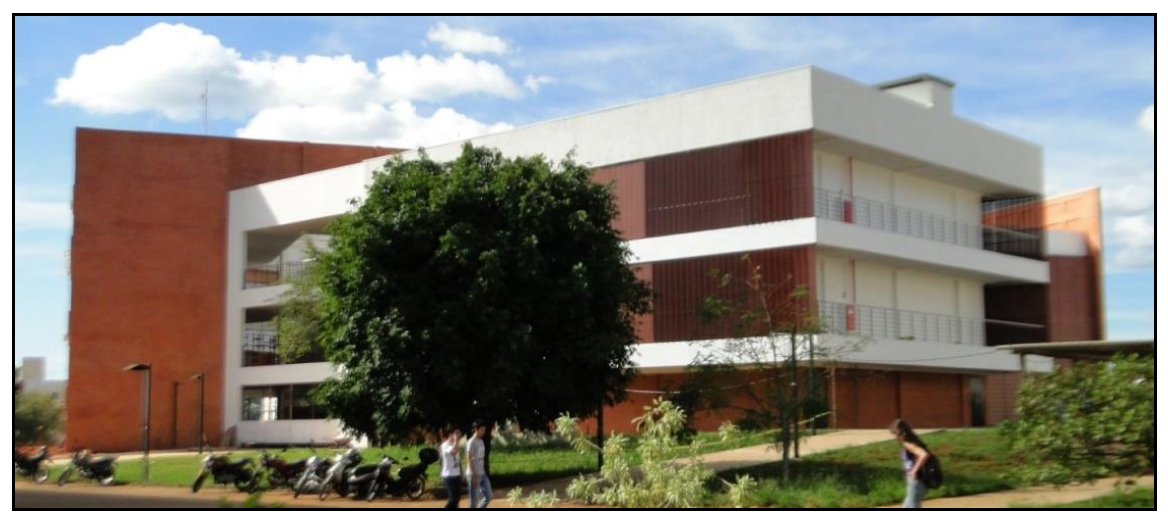

Fonte: UFU (2014).

\section{MÉTODO}

O estudo de caso consistiu na análise das planilhas orçamentárias e plantas arquitetônicas de cada edificação (1 AMC, $1 \mathrm{BCG}$ e 5SSM).

Para a estrutura básica de um edifício a partir do ponto de vista econômico, o custo de construção é de aproximadamente $25 \%$ correspondente às instalações e $75 \%$ correspondente à parte civil (espaços) sendo que $25 \%$ são planos horizontais e 50\% verticais (MASCARÓ, 2004). Os edifícios foram divididos em quatro partes fundamentais, três delas como Mascaró sugeriu: planos horizontais, planos verticais e instalações; e outros que compreendem projetos, serviços preliminares, diversos, limpeza e omissos. Compõe os planos horizontais: estrutura resistente, contrapiso, piso; e os planos verticais: alvenaria, isolamento e pilares estruturais, acabamentos verticais (rebocos, pintura e azulejos), caixilharia e esquadrias internas e externas.

As variações de custo com as formas do edifício fornece o índice de compacidade, que é definido como a relação entre o perímetro de um círculo de igual área do projeto e o perímetro das paredes exteriores do projeto (Mascaró, 1995), como pode ser observado na Equação 1.

$$
I_{c}=\frac{P_{c} \times 100}{P_{p}}
$$

onde, $I_{c}=$ índice de compacidade;

$\mathrm{P}_{\mathrm{c}}=$ perímetro de um círculo de igual área do projeto;

$\mathrm{P}_{\mathrm{p}}=$ perímetro das paredes exteriores, em planta, do projeto.

Matematicamente o índice máximo de compacidade é de $100 \%$ e corresponde a um projeto de planta circular. Mas segundo Mascaró (1995), quanto mais próximo de 88,5\% (planta quadrada), esteja o índice de compacidade de um projeto, menores serão os custos de construção e menores também as perdas e ganhos térmicos indesejáveis. Entre 70 e $88 \%$ os custos variam pouco enquanto que entre 30 e $40 \%$ os custos variam muito. Isto é, para um edifício econômico não é necessário que seja quadrado, mas que se observe que, dentro de certos limites, se é necessário boa ventilação e iluminação, os 
acréscimos nos custos serão tão pequenos que podem ser desconsiderados (MASCARÓ, 1995).

Para a influência da variação da altura e do sistema de circulação do edifício no custo de construção analisou-se as plantas arquitetônicas.

\section{RESULTADOS E DISCUSSÃO}

\subsection{A estrutura básica de um edifício a partir do ponto de vista econômico}

Em relação a estrutura básica de um edifício, como as edificações foram divididas em quatros partes (planos horizontais e verticais, instalações e outros), as porcentagens dessas partes podem ser observadas na Tabela 1 e a composição dos planos horizontais e verticais podem ser observadas na Tabela 2 .

Tabela 1: Participação de planos horizontais e verticais, instalações e outros nos custos, em \%.

\begin{tabular}{|c|c|c|c|c|}
\hline Edificações & Planos Horizontais & Planos Verticais & Instalações & Outros \\
\hline \multirow{2}{*}{ 1AMC } & 41,33 & 36,66 & \multirow{2}{*}{12,66} & \multirow{2}{*}{9,35} \\
\hline & \multicolumn{2}{|c|}{77,99} & & \\
\hline \multirow{2}{*}{$1 \mathrm{BCG}$} & 29,79 & 38,42 & \multirow{2}{*}{13,14} & \multirow{2}{*}{18,65} \\
\hline & & & & \\
\hline \multirow{2}{*}{$5 S S M$} & 23,08 & 39,61 & \multirow{2}{*}{14,69} & \multirow{2}{*}{22,62} \\
\hline & \multicolumn{2}{|c|}{62,69} & & \\
\hline
\end{tabular}

Fonte: A autora.

Tabela 2: Participação média das diferentes rubricas nos planos horizontais e verticais nos blocos analisados e segundo Mascaró (1995) (\%).

\begin{tabular}{|l|c|c|c|c|}
\hline \multirow{2}{*}{ Elemento construtivo } & \multicolumn{3}{c|}{ Edificações } & \multirow{2}{*}{ Segundo Mascaró } \\
\cline { 2 - 5 } & 1AMC & 1BCG & 5SSM & \\
\hline Planos Horizontais & & & & \\
\hline Estrutura resistente & 59,24 & 57,93 & 54,25 & 65 a 75 \\
\hline Contrapiso e piso & 30,08 & 19,61 & 26,89 & 18 a 36 \\
\hline Telhado & 10,68 & 22,46 & 18,86 & \\
\hline Total & 100,00 & 100,00 & 100,00 & 100,00 \\
\hline \multicolumn{1}{|c|}{ Planos Verticais } & & & & \\
\hline Alvenaria, isolamento e pilares & 47,75 & 54,39 & 37,22 & 25 a 35 \\
\hline Acabamentos (reboco, pintura e azulejos) & 27,01 & 18,78 & 27,85 & 30 a 40 \\
\hline Caixilharia e esquadrias & 20,60 & 26,83 & 34,93 & 30 a 40 \\
\hline Elevador & 4,64 & 0 & 0 & \\
\hline Total & 100,00 & 100,00 & 100,00 & 100,00 \\
\hline
\end{tabular}

Fonte: A autora. 
Assim, pode-se observar que, apesar da parte "Outros" ser significativa, nos diferentes projetos arquitetônicos têm-se diferentes participações do orçamento em cada plano e instalações.

O bloco 1AMC tem forma de T e é comprido nas duas direções (Figura 4), além de ter corredores nas laterais em uma das direções e jardineiras laterais contornando quase todo o prédio. Isso faz com que a participação dos planos horizontais exceda o esperado e os verticais sejam menores, mas somados apresentam a participação esperada de acordo com os estudos do Mascaró (2004).

Figura 4 - Forma de T do bloco 1AMC.

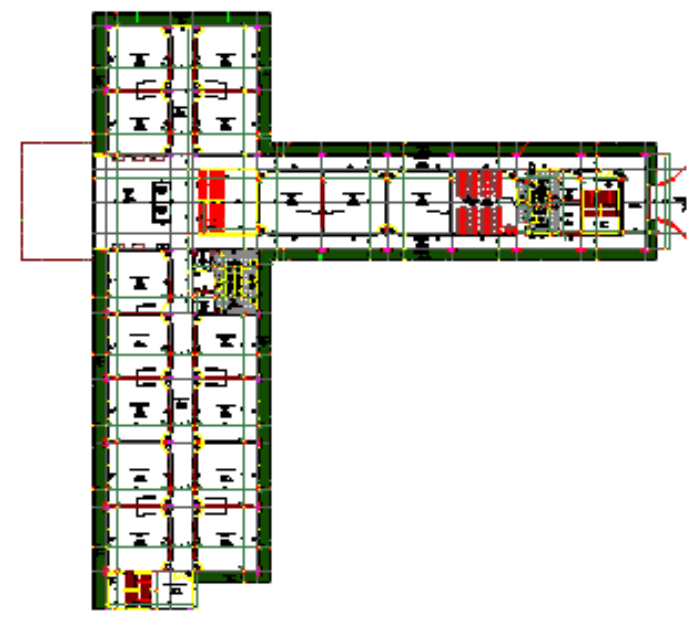

Fonte: UFU (2010).

A Figura 6 mostra o bloco 1BCG que apresenta projeto geométrico diferenciado em formato de leque, com corredores centrais e rampas. Os custos dos planos horizontais são menores que dos verticais.

Figura 5 - Forma do bloco 1BCG.

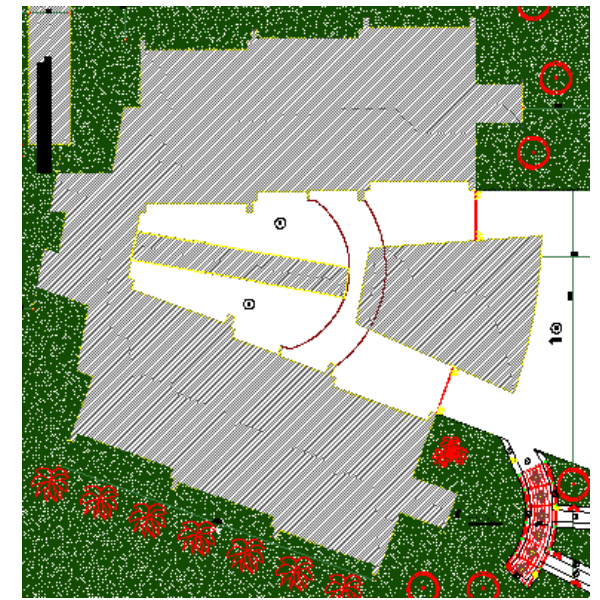

Fonte: UFU (2009). 
Uma sugestão para se diminuir os custos com planos horizontais é diminuir a área dos corredores, modificando projeto arquitetônico dos edifícios, e eliminar divisórias, fazendo espaços germinados.

Nos planos horizontais, o custo maior cabe à estrutura resistente, assim, seria interessante ajustar o tipo de estrutura escolhida aos vãos que ela deve vencer e as cargas que deve suportar, para uma economia. Nos planos horizontais, contrariando Mascaró, os blocos analisados apresentam maior custo na alvenaria, isolamento e pilares e não com acabamento e aberturas, mas estes podem ter seus custos reduzidos utilizando materiais e elementos alternativos.

\subsection{O tamanho e a forma dos compartimentos no custo das edificações}

Nas edificações da UFU estudadas, os índices de compacidade calculados usando a equação (1) foram:

$$
\begin{aligned}
1 \mathrm{AMC}-\mathrm{IC} & =59,29 \% \\
1 \mathrm{BCG}-\mathrm{IC} & =44,72 \% \\
5 \mathrm{SSM}-\mathrm{IC} & =58,10 \%
\end{aligned}
$$

Os índices de compacidade das edificações analisadas não estão na faixa ótima, de compacidade alta, nem na outra faixa extrema cujas compacidades são muito baixas, mas apresentam qualidade em habitabilidade pela boa iluminação e ventilação natural. Assim, são econômicas nesse aspecto.

Em relação aos compartimentos, desde que a função seja desempenhada, a relação perímetro/área deve ser maximizada.

\subsection{Influência da variação da altura do edifício no custo da construção e do sistema de circulação no custo do edifício}

O bloco 1AMC apresenta térreo mais três pavimentos, sendo que, como este é em forma de T, uma das direções tem os quatro pavimentos e a outra apenas dois. O elevador está localizado de forma que atenda as duas direções, em função da acessibilidade, e foi feita a rampa que posteriormente atenderá outros dois blocos.

Há dois tipos de corredores: dos dois lados das salas, sendo que para cada sala há duas portas para acessá-los, uma de cada lado da sala (Figura 6) e no meio servindo para salas à direita e à esquerda (Figura 7).

Figura 6 - Corredores de circulação dos dois lados das salas.

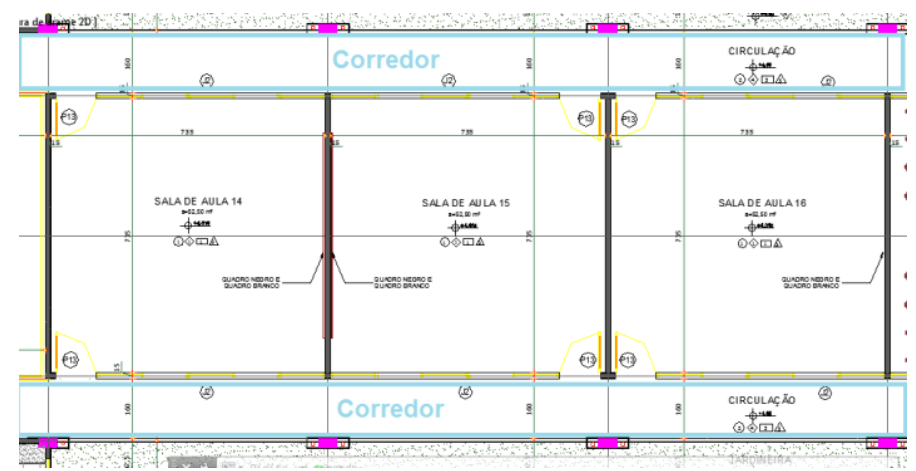

Fonte: UFU (2010). 
Figura 7 - Corredores centrais de circulação.

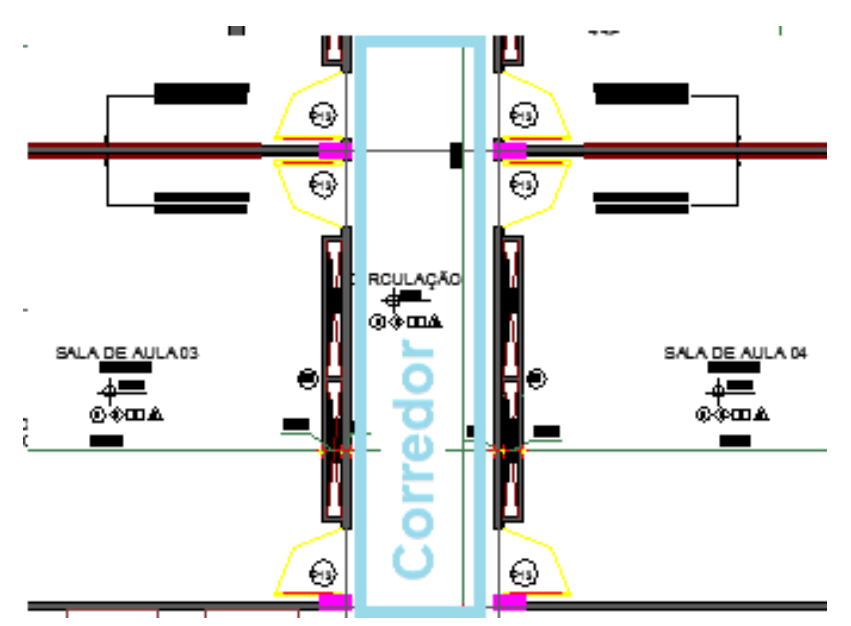

Fonte: UFU (2010).

Os corredores laterais se apresentam como solução econômica quando abertos, por permitirem a ventilação cruzada, mas devem ser restritos em no máximo quatro pavimentos (com térreo), como é o caso do bloco $1 \mathrm{AMC}$, pois com o aumento da altura há aumento na velocidade do vento o que inclina as chuvas ao extremo de perder a necessária proteção.

Os blocos 1BCG e 5SSM apresentam térreo mais dois pavimentos, e não têm elevador, mas há rampas e escadas. Nos blocos há pelo menos duas escadas, para que se possa ter acesso aos outros pavimentos com facilidade, há rampas para acessibilidade e no bloco 1AMC há elevadores.

Os corredores do bloco 1BCG são centrais (Figura 8) e os corredores do 5SSM são laterais (Figura 9).

Figura 8 - Corredor central, bloco 1BCG.

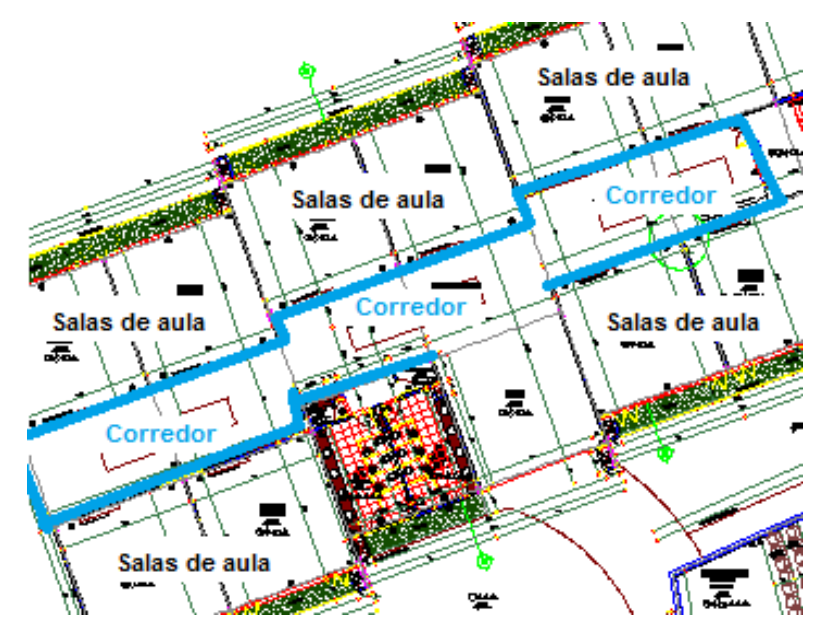

Fonte: UFU (2009). 


\section{Figura 9 - Corredores laterais, bloco 5SSM.}

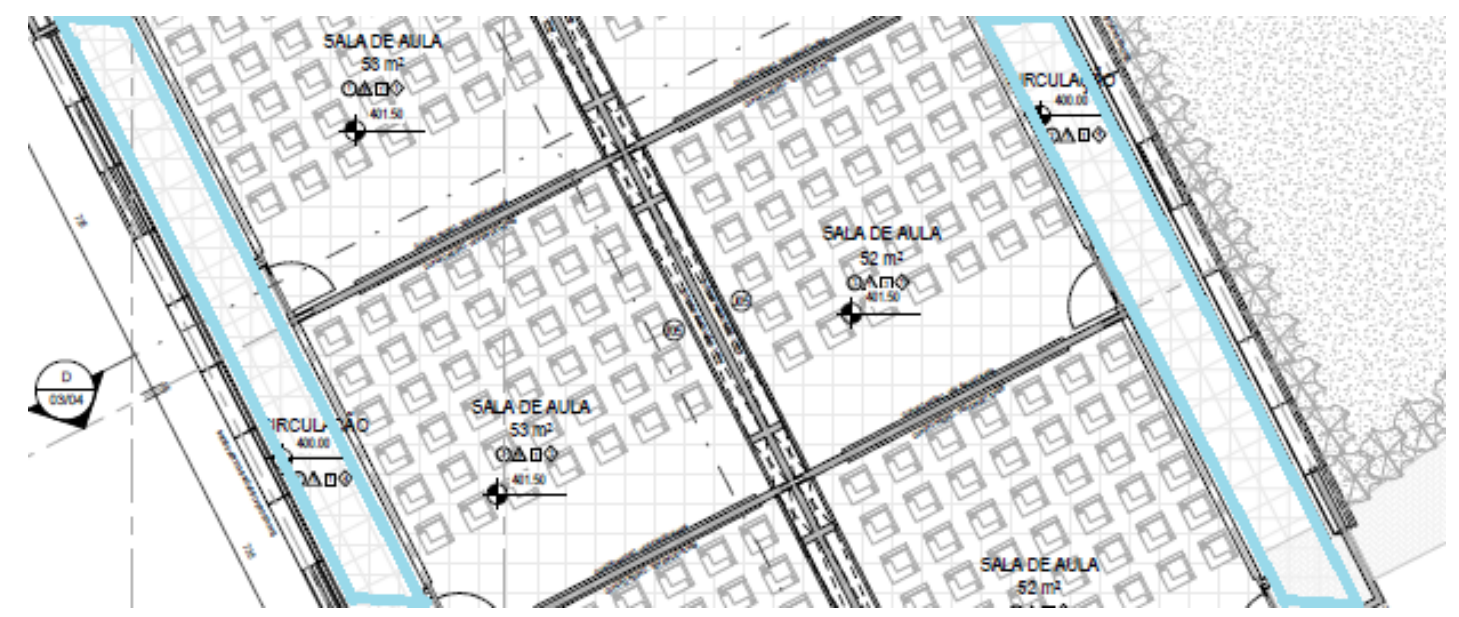

Fonte: UFU (2009).

Os corredores têm grande extensão (comprimento) se os núcleos de circulação vertical (escadas, elevadores e rampas) estiverem mais concentrados. Isto é, se a edificação é comprida em uma direção, e o núcleo de circulação vertical se concentra em uma das extremidades, os corredores têm que ser compridos para atender a circulação horizontal de todo o pavimento.

Por mais que o projetista acredite que a área de circulação é grande, não será diminuindo sua largura que solucionará o problema, e sim mudando o projeto arquitetônico.

\section{CONSIDERAÇÕES FINAIS}

Atualmente os projetos arquitetônicos são marcados pela interação dele com o local de intervenção, a relação dos espaços interiores e exteriores para com a organização dos planos horizontais e verticais e à materialização do edifício, mas não se deixa de lado a estética que este pode agregar ao local que é implantado.

As edificações foram analisadas por meio dos projetos arquitetônicos e planilhas orçamentárias e foi obtido que os projetos apresentam boas escolhas frente às decisões arquitetônicas. Apesar das limitações observadas quanto aos custos de construção dos planos verticais, planos horizontais e instalações, estes estão dentro do esperado. Mas quando se analisa os elementos construtivos de cada plano tem-se uma diferença um pouco acentuada.

Os custos podem ser reduzidos se as formas de algumas partes dos planos forem modificadas, diminuindo dimensões ou alterando a forma do projeto e/ou utilizar materiais e elementos alternativos, pois estes encarecem os planos e instalações.

Mesmo os blocos apresentando geometria diferenciada, estes têm índice de compacidade econômico, mas deve-se repensar as formas muito alongadas que causam incrementos de custos consideráveis (corredores e as jardineiras no caso do bloco 1AMC). 
Apesar dos corredores do bloco 1AMC e 5SSM serem compridos, e estarem nas duas laterais, esses corredores são eficazes na circulação de ar (ventilação cruzada). Para maiores mudanças é necessário modificar os projetos.

Sendo assim, para um projeto econômico o importante é analisar os vários componentes de um edifício e pensar de forma a minimizar os custos prezando pela qualidade, estética e funcionalidade da edificação.

\section{AGRADECIMENTOS}

A equipe de engenheiros e arquitetos da Diretoria de Infraestrutura da UFU, que me proporcionou realizar este estudo enquanto estagiária.

\section{REFERÊNCIAS}

CUNHA, E. G. da. A tecnologia no processo de concepção arquitetônica contemporânea: análise de três obras de Norman Foster. Arquitetura Revista, São Leopoldo, v. 4, n. 1, p.4965, janeiro/junho 2008. Disponível em: <http://revistas.unisinos.br/index.php/arquitetura/article/view/5462>. Acesso em: 02 fev. 2014.

UFU (Universidade Federal de Uberlândia). Diretoria de Infraestrutura. Projeto arquitetônico bloco multiuso 1AMC, 1APM e 1CCG. UFU, 2010.

Projeto arquitetônico blocos 5SSM e 1BCG. UFU, 2009.

. Banco de fotos - Técnicos em edificação. UFU, 2014.

MASCARÓ, J. L. O Custo das Decisões Arquitetônicas. 3. ed. Porto Alegre: JLM, 2004. 180p.

O custo das decisões arquitetônicas no projeto de hospitais. Brasília, 1995. 